\begin{abstract}
Iranica
Abstracta Iranica Revue bibliographique pour le domaine irano-aryen

Volume 37-38-39 | 2018

Comptes rendus des publications de 2014-2016
\end{abstract}

\title{
Rika Gyselen (éd.). Argenterie, documents et monnaies de tradition sassanide
}

Julien Cuny

\section{(2) OpenEdition}

Édition électronique

URL : http://journals.openedition.org/abstractairanica/46314

DOI : 10.4000/abstractairanica.46314

ISBN : 1961-960X

ISSN : 1961-960X

Éditeur :

CNRS (UMR 7528 Mondes iraniens et indiens), Éditions de l'IFRI

Référence électronique

Julien Cuny, «Rika Gyselen (éd.). Argenterie, documents et monnaies de tradition sassanide », Abstracta Iranica [En ligne], Volume 37-38-39 | 2018, document 40, mis en ligne le 30 décembre 2018, consulté le 26 septembre 2020. URL : http://journals.openedition.org/abstractairanica/46314 ; DOI : https:// doi.org/10.4000/abstractairanica.46314

Ce document a été généré automatiquement le 26 septembre 2020

Tous droits réservés 


\title{
Rika Gyselen (éd.). Argenterie, documents et monnaies de tradition sassanide
}

\author{
Julien Cuny
}

\section{RÉFÉRENCE}

Rika Gyselen (éd.). Argenterie, documents et monnaies de tradition sassanide. Bures-surYvette : Groupe pour l'Étude de la Civilisation du Moyen-Orient, 2014. 190 p. (Res Orientales, XXII)

1 Comme la précédente livraison, ce numéro des Res Orientales est consacré à la civilisation sassanide jusqu'aux débuts l'Islam. On notera tout d'abord le deuxième article de Ph. Gignoux consacré à la publication de documents issus d'une 'archive' du Tabaristan datée du $8^{\text {ème }} \mathrm{s}$. de n.è. (cf. c.r. de Rika Gyselen (ed.). Objets et documents inscrits en pārsīg (Res Orientales, XXI) : dix nouveaux documents, tous de contenu juridique comme les précédents, sont présentés et une traduction préliminaire est proposée. On ne peut assez insister sur la valeur exceptionnelle de cette documentation pour l'étude du droit et des pratiques judiciaires dans le monde sassanide. L'A. annonce au moins un autre article pour en achever l'édition princeps. La contribution de D. Weber traite d'une autre collection de documents pehlevis du début de l'époque islamique traditionnellement appelée "'archive' pehlevie de Berkeley». Bien que produits par une communauté iranienne sous la domination politique des nouveaux maitres musulmans, ces documents montrent peu l'influence de ces derniers : D. Weber en recense ici quelques exceptions.

2 M. Blet-Lemarquand et $R$. Gyselen présentent les résultats des analyses de la composition élémentaire d'un échantillon de 22 monnaies de cuivre et d'alliages cuivreux arabo-sassanides de la Bibliothèque Nationale de France. L'article bénéficie d'une très utile remise en contexte et même de la publication d'un nouveau sceau de 
mowūh (='bureau des mages', anciennement lu maguh) peut-être daté du début de l'époque islamique. Si la composition variée du métal des monnaies reflète la diversité des types émis, certaines tendances semblent clairement caractériser des émissions particulières (par ex. la pureté en cuivre des monnaies frappées par les gouverneurs arabes), mais les AA. appellent à un élargissement de l'échantillon pour appuyer leurs hypothèses. Dans le troisième article, R. Gyselen publie les inscriptions de deux rhytons d'argent en tête de sanglier formant une paire. L'étude est particulièrement utile pour le riche catalogue de la vaisselle en argent sassanide inscrite dont l'A. a compilé l'ensemble des informations disponibles dans une littérature très éclatée.

\section{AUTEURS}

\section{JULIEN CUNY}

Conservateur au Musée du Louvre, Paris 